\title{
Reporting of complex interventions in clinical trials: development of a taxonomy to classify and describe fall-prevention interventions
}

\author{
Sarah E Lamb ${ }^{1,2^{*}}$, Clemens Becker ${ }^{3}$, Lesley D Gillespie ${ }^{4}$, Jessica L Smith ${ }^{1}$, Susanne Finnegan ${ }^{1}$, Rachel Potter ${ }^{1}$ and \\ Klaus Pfeiffer ${ }^{3}$ for The Taxonomy Investigators
}

\begin{abstract}
Background: Interventions for preventing falls in older people often involve several components, multidisciplinary teams, and implementation in a variety of settings. We have developed a classification system (taxonomy) to describe interventions used to prevent falls in older people, with the aim of improving the design and reporting of clinical trials of fall-prevention interventions, and synthesis of evidence from these trials.

Methods: Thirty three international experts in falls prevention and health services research participated in a series of meetings to develop consensus. Robust techniques were used including literature reviews, expert presentations, and structured consensus workshops moderated by experienced facilitators. The taxonomy was refined using an international test panel of five health care practitioners. We assessed the chance corrected agreement of the final version by comparing taxonomy completion for 10 randomly selected published papers describing a variety of fallprevention interventions.
\end{abstract}

Results: The taxonomy consists of four domains, summarized as the "Approach", "Base", "Components" and "Descriptors" of an intervention. Sub-domains include; where participants are identified; the theoretical approach of the intervention; clinical targeting criteria; details on assessments; descriptions of the nature and intensity of interventions. Chance corrected agreement of the final version of the taxonomy was good to excellent for all items. Further independent evaluation of the taxonomy is required.

Conclusions: The taxonomy is a useful instrument for characterizing a broad range of interventions used in falls prevention. Investigators are encouraged to use the taxonomy to report their interventions.

\section{Background}

Reduction of falls in older people is an important health care target in many countries. However, the aetiology of falls in older people is not fully understood. Although some falls result from a single factor, many are caused by an interaction between multiple factors [1]. As a consequence, a wide variety of approaches to prevention and management have emerged, most of which are "complex interventions" [2]. Complex interventions are usually described as interventions that contain several interacting components [2]. Despite many clinical trials which have

\footnotetext{
* Correspondence: s.lamb@warwick.ac.uk

'Warwick Clinical Trials Unit, University of Warwick, Gibbet Hill Campus, Coventry, UK

Full list of author information is available at the end of the article
}

identified effective interventions, translation into clinical practice has been slow [3]. There are many potential barriers to implementation of new interventions. Poor reporting of interventions in clinical trials can result in practitioners being unable to replicate the intervention. Researchers evaluating interventions in meta-analysis lack an internationally agreed framework for conceptualizing the main forms and important components of fall-prevention techniques, limiting the ability to draw meaningful comparisons and identify factors associated with success.

Several sets of international guidance have highlighted the importance of documenting and conceptualizing the influential components of an intervention, recognizing the importance of these steps in evaluation and understanding the potential for generalization of an intervention $[4,5]$.

\section{C) Biomed Central}

(C) 2011 Lamb et al; licensee BioMed Central Ltd. This is an Open Access article distributed under the terms of the Creative Commons Attribution License (http://creativecommons.org/licenses/by/2.0), which permits unrestricted use, distribution, and reproduction in any medium, provided the original work is properly cited. 
However, this documentation and conceptualization is not simple, particularly when trials may be from countries with different health and social care services.

The aim was to develop a classification system to characterize the major influential components of fallprevention interventions and promote consistency of reporting across international boundaries. We wished to encourage investigators to report all fall prevention interventions in a standardised and comprehensive manner, and to produce a taxonomy that could be used to classify existing and future interventions. We report the process of development, involving repeated testing and refinement, from the initial stages of design through to the final version of the taxonomy.

The study was developed through the Prevention of Falls Network Europe (ProFANE) project, a collaborative project to reduce the burden of fall injury in older people through excellence in research and promotion of best practice [6]. The network activities were funded by the European Commission, but link clinicians, members of the public, and researchers worldwide.

\section{Methods}

Classification systems are of two major types-typologies and taxonomies. Typologies are theoretically driven classification schemes. A taxonomy necessitates identifying characteristics that can be objectively measured in realworld circumstances, and have sufficient variance to demonstrate meaningful differences [7]. We aimed to develop an internationally accepted taxonomy. Sartorius [7] provides useful guidance on the development of taxonomies, highlighting the importance of broad agreement on the content and framework to ensure compliance with the intent and method of classification, and the need for an accompanying glossary defining operational terms. Our method was an iterative process, comprising a phase of development, followed by a period of refinement and finalisation. The process was informed and approved by international expert consensus throughout its span, the nature of the consensus building techniques varied during the project, but formal nominal group methods were implemented at key stages [8]. The consensus panel included 33 representatives of the academic, policy, practice, and user communities drawn from a range of disciplines and countries in Australasia, Europe and North America (detailed at the end of the manuscript). Disciplines included were medicine, physiotherapy, occupational therapy, nursing, psychology, public health, exercise physiology, statistics and epidemiology.

\section{Stage 1: Developing the taxonomy}

The process for developing the taxonomy is summarized in Figure 1. In the initial stages, a draft hierarchical framework of classification that identified the major domains was developed by a small group of investigators (SEL, EJS, KP, CB). This draft framework included the domain headings: "Approach", "Base", "Components" and "Descriptors". These domains provide the overall structure and framework to the taxonomy. The proposed framework was discussed and approved by a meeting of 50 academics and practitioners engaged in research in falls prevention in Manchester in 2004. Definitions were developed for each domain, along with sub-domains. The intention was that sub-domains would represent meaningful differences in the ways in which interventions had or could be delivered. Within each sub-domain the taxonomy was further characterized to provide more detailed levels of information on the service delivery model which we labeled as categories. The development was informed by close reference to the published literature to ensure the taxonomy was sufficiently comprehensive to describe the variety of interventions, settings and service delivery models reported in the research literature. Firstly, we identified all trials published in full and in English included in Gillespie et al [9], and used a random sampling method to select half of these $(\mathrm{N}=28$, [10-37]). We retained the remaining papers $(\mathrm{N}=27)$ for validation studies in later components of the study. Second, we undertook a broader search of the nonrandomised and grey literature search strategy reported in [38] to identify new or untested approaches to fall prevention. Where possible, we utilized existing international classification systems to provide category definitions and headings [39-43], and sourced additional definitions from the Medical Subjects Headings (MeSH) browser of the US National Library of Medicine. In some domains of the taxonomy, there were no pre-existing classification systems, and these were developed by consulting members of the expert panel, matching expertise to the areas requiring development. At each stage of the process, the rationale, definitions and instructions for completion of the various components of the taxonomy was documented, and turned into a draft instruction manual.

\section{Stage 2: Refining and agreeing the final version of the taxonomy and manual}

The first version of the taxonomy and manual was circulated prior to a formal two-day consensus meeting of 33 international experts. We utilized a modified nominal group technique, facilitated by experienced health services researchers, in which panel members were asked to consider eight questions relating to the proposed taxonomy (shown in Table 1). The relevance of the domains, sub-domains and categories were agreed and prioritized by consensus panel. Only the most important categories were retained in the taxonomy, recognizing the need to balance detail against practical issues of completion and 


\section{Development of the Classification System}

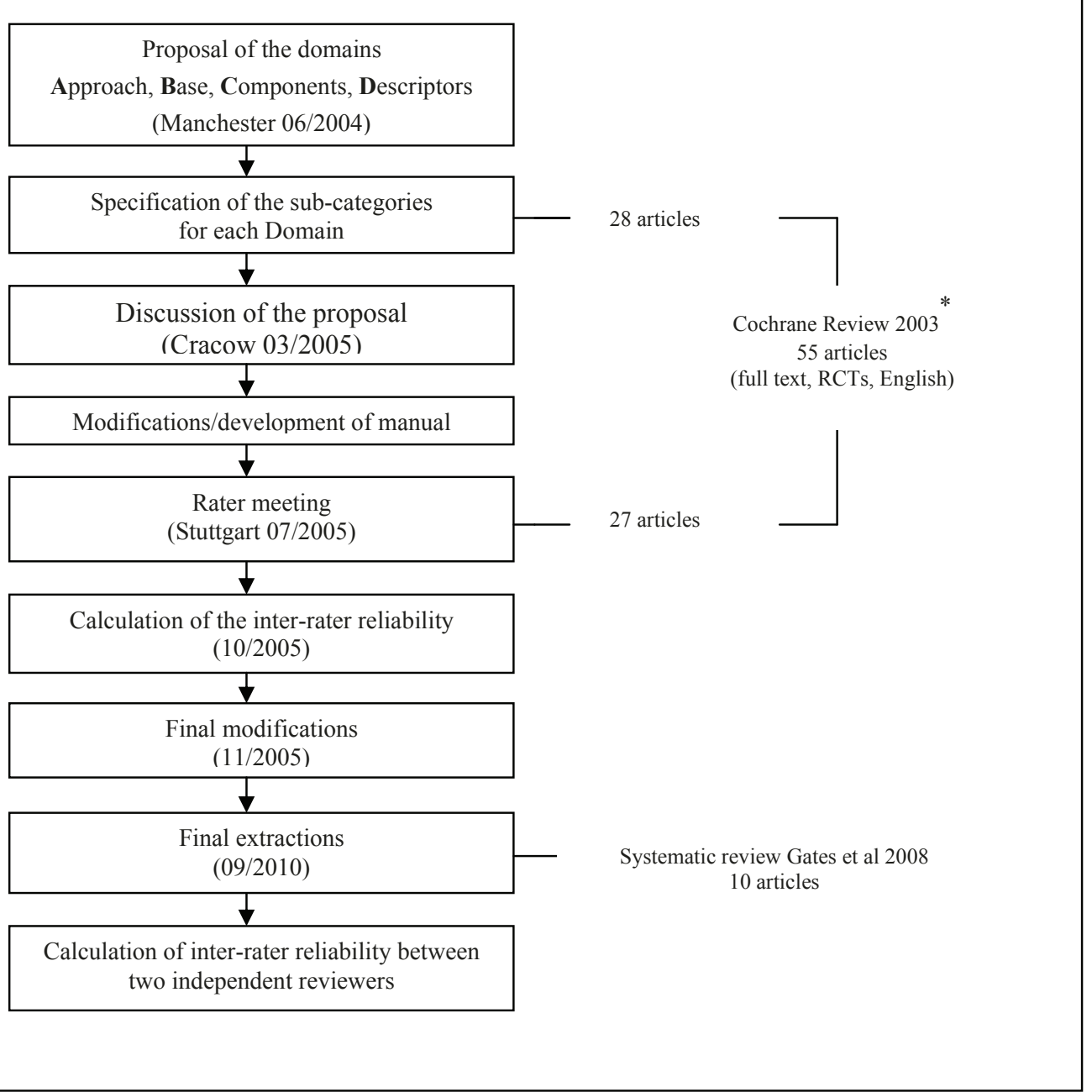

* Gillespie LD, Gillespie WJ, Robertson MC, Lamb SE, Cumming RG, Rowe BH. Interventions for preventing falls in elderly people. Cochrane Database of Systematic Reviews 2003, Issue 4 . Art. No.: CD000340. DOI: 10.1002/14651858.CD000340 .

Figure 1 Development of the Classification System.

Table 1 Questions used to structure the modified nominal group

\begin{tabular}{|c|c|}
\hline 1. & Can current interventions be included (i.e. is the taxonomy complete)? \\
\hline 2. & $\begin{array}{l}\text { Is the proposed classification clear and meaningful? Does the typology include all potentially relevant and important factors, grouped in a } \\
\text { meaningful manner? }\end{array}$ \\
\hline 3. & $\begin{array}{l}\text { Is the identification of factors likely to be influential in determining clinical outcome, generalisability and implementation (i.e. the model) } \\
\text { acceptable? }\end{array}$ \\
\hline 4. & Does the model adequately reflect the complexity of current interventions? \\
\hline 5. & Can future interventions be included in the model? \\
\hline 6. & Is the classification compatible with other classification systems? \\
\hline 7. & Is it feasible to report the required information in articles/reports/ \\
\hline
\end{tabular}


ease of communication. The panel also considered the future use of the taxonomy and its capacity to assimilate new and emerging areas of practice.

The taxonomy and manual were then tested using the remaining 27 articles retained after our search of trials published in the Cochrane review [9,44-70]. Data on the intervention characteristics from these 27 papers were extracted by five academic health practitioners who had not been involved in development stages of the taxonomy (the test panel). These practitioners included disciplines of medicine, physiotherapy, occupational therapy, psychology and nursing. Each rater was provided with a copy of the taxonomy manual, and a recording form. In addition, a number of papers were replicated across the raters to enable estimation of the test re-test reliability of the taxonomy. A cut-off of poor agreement between raters (a cut of kappa $<0.41$ as per Landis and Koch [71]) was used to indicate areas of the taxonomy and manual requiring revision. We also worked with individual raters to determine areas of the manual and taxonomy that lacked clarity, were difficult to complete, or were incomplete. Results of the panel test were reported back to a group of 12 of the original members of the expert panel to agree the final format and manual for the taxonomy.

Finally, two independent reviewers completed a taxonomy for the interventions reported in ten randomised controlled trials selected at random from the systematic review of Gates et al [72-82], to determine the agreement and chance corrected agreement (kappa) for each sub-domain. Agreement was calculated over all categories included in each sub-domain, according to Landis and Koch [71]. Chance corrected agreement (kappa) was then established using SPSS (version 17) for each subdomain for all ten papers. For each paper we then determined the frequency of items (kappa values) contained within each kappa banding (poor, fair, moderate, good or very good) as described by Altman [83]. The frequencies calculated were then added together across all ten papers and converted into a percentage. These results therefore show the percentage of items (kappa values) across all ten papers within each kappa banding.

\section{Results}

The full taxonomy including the recording form and instruction manual are provided in Additional Files, 1 and 2. A description of the domains, sub-domains, and categories in each sub-domain are given in Table 2, along with a brief synopsis of the consensus justification for inclusion within the taxonomy. Agreement between the two independent raters for extraction for the final version of the taxonomy was good to excellent for all sub-domains. In over $90 \%$ of cases chance corrected agreement was very strong between the two independent raters $(\mathrm{kappa}=0.81-1.00)($ Table 3$)$.

\section{Discussion}

The evaluation of complex interventions is an infant science. An inability to identify, define and communicate the potentially important components of falls prevention interventions has the potential to hinder development of research and uptake into clinical practice. We have identified key characteristics of interventions that we believe should be described alongside the publication of a randomised controlled trial of fall-prevention interventions. Many of the domains, sub-domains and categories are transferable to other similar interventions.

The taxonomy represents judgments in determining essential from non-essential information, and balances the need for brevity and simplicity against complexity and detail. There is no single accepted method to develop a taxonomy. Empirically based classification requires data, and in this case, data sources were publications of randomised controlled trials of fall-prevention interventions, meta-analyses and qualitative studies. This was supplemented by extensive involvement of experts, which is acknowledged as essential in developing taxonomies [84]. Elicitation of expert knowledge from consensus methods can be problematic [8]. We protected against predomination of individual's opinion by using a modified nominal group technique, guided by pre-specified questions and independent facilitation [8]. The modified nominal group technique was selected in preference to the Delphi method, as it allows discussion between experts to gain consensus [8].

The taxonomy went through several iterations, being refined by a diverse group of international experts at different time points. There were a number of internationally agreed classification systems already in existence, and we used these wherever possible. These included the controlled vocabulary (Medical Subject Headings (MeSH)) used to index MEDLINE. The performance of the draft taxonomy was assessed using retrospective data extraction from published papers. The validation sample contained a variety of intervention types. Whilst we have allowed for the possibility of new areas emerging within the taxonomy, further refinements will be required. For example, further refinement of the selection criteria section might include data on screening tools used, for example whether the tool intends to capture single or repeat fallers, or aims to identify osteoporotic fracture risk. We also accept that the sub-domains of the taxonomy may not be entirely distinctive in all situations, but that for the majority of situations it is fit for purpose. We intend to review the taxonomy in five years time and welcome feedback on the structure and content. 
Table 2 Domains and sub-domains of the taxonomy of fall-prevention interventions

\begin{tabular}{|c|c|}
\hline Domain & Sub-domain \\
\hline $\begin{array}{l}\text { Approach: describes the theoretical approach in terms of the primary } \\
\text { aims, whether a population or individual approach has been used, and } \\
\text { whether selection or targeting criteria have been used to identify cases or } \\
\text { populations. }\end{array}$ & $\begin{array}{l}\text { Primary aims of the intervention being developed } \\
\text { Primary selection criteria used for case identification. }\end{array}$ \\
\hline $\begin{array}{l}\text { Base: describes where participants have been selected from, where the } \\
\text { intervention is delivered and by whom }\end{array}$ & $\begin{array}{l}\text { Recruitment or case identification: the site at which participants of the } \\
\text { intervention were identified; } \\
\text { Primary site of delivery: the site at which the majority of the } \\
\text { intervention is delivered or targeted. } \\
\text { Interventions delivered by: describes the individuals (professionals, } \\
\text { trained professionals, etc) who deliver the majority of the intervention }\end{array}$ \\
\hline $\begin{array}{l}\text { Components: describes variations in assessments used for deciding } \\
\text { treatments, the conceptual basis, and different methods of combining } \\
\text { interventions }\end{array}$ & $\begin{array}{l}\text { Assessments that are used } \\
\text { Combination of interventions }\end{array}$ \\
\hline $\begin{array}{l}\text { Descriptors: describes each of the components delivered in the control } \\
\text { including sub-classifications that are considered potentially important }\end{array}$ & $\begin{array}{l}\text { Description of control group or sham interventions } \\
\text { Description of the test interventions components }\end{array}$ \\
\hline
\end{tabular}

The taxonomy is intended for a number of purposes, including to assist with data extraction alongside metaanalysis of research data, reporting of interventions tested in research studies, and in the process of development of interventions. The list is purposefully not exhaustive. The most recent update of the CONSORT guidelines for reporting clinical trials necessitates reporting on the main elements of complex interventions [5]. The challenges of reporting complex interventions have been recognised for sometime. The Medical Research Council (MRC) first published a framework for reporting and evaluating complex interventions in 2000 [85]. Although the MRC framework stresses the importance of accurate reporting, little operational guidance is provided. A recent suggestion has been to use graphical techniques to present key features of the timeline and content of interventions [4], a technique which can be expanded to a number of non-pharmacological interventions. In comparison, our method, which has more limited application as it focuses on fall-prevention interventions, is structured to ensure ease of complete reporting (by way of yes/no answers), uses standard internationally transferable set of definitions to describe the intervention components, settings and populations tested; and provides a more detailed description of intervention. Replication of interventions should be easier to achieve, although this assumption requires testing. We anticipate that similar

Table 3 kappa agreement for the final extractions by two raters

\begin{tabular}{ccc}
\hline Kappa & Strength of agreement & Frequency (\%) \\
\hline $0.81-1.00$ & Very Good & 90.3 \\
\hline $0.61-0.80$ & Good & 2.1 \\
\hline $0.41-0.60$ & Moderate & 0.9 \\
\hline $0.21-0.40$ & Fair & 0.3 \\
\hline$<0.20$ & Poor & 6.5 \\
\hline
\end{tabular}

methods could be developed in other fields. The taxonomy is complementary to but does not replace the Consort Guidance on the reporting of complex interventions [5].

Subsequently, the taxonomy has proved useful in a number of Cochrane and other high quality systematic reviews, and has enabled identification and pre-specification of important aspects of service configuration and intervention delivery [9,72,86-88]. We have also used the taxonomy as the framework for a UK national survey of falls services [3]. Authors of trials are encouraged to register details of their interventions using the taxonomy in a prospective format (open registration is available at http://www.warwick.ac.uk/go/fallstaxonomy), and to utilize the taxonomy to ensure accurate, complete and useful intervention reporting.

\section{Conclusion}

We have developed a taxonomy to describe and classify fall-prevention interventions, with sufficient breadth to capture elements of the intervention that are thought influential in determining effectiveness. This was achieved through a mix of methods, including expert consensus, literature reviews, and validation by test panels.

\section{Additional material}

Additional file 1: Manual for the fall prevention classification system

Additional file 2: Taxonomy to describe and conceptualise fall prevention interventions

\section{Acknowledgements and funding}

The authors were participants in the Prevention of Falls Network Europe (ProFaNE) Thematic Network, which was a project within Key Action 6 (The Ageing Population and Their Disabilities), part of the European Union's 
Quality of Life and Management of Living Resources funded by the European Commission (QLRT-2001-02705). The content of the manuscript does not represent the opinion of the European Community, and the Community is not responsible for any use that might be made of the information made in the text.

\section{Taxonomy investigators}

We thank all of the taxonomy investigators, all of whom participated in the expert consensus groups, panels or other aspects of the data analysis. Ballinger C, Becker C, Benevenuti F, Bramhall C, Bonnefoy M, Cameron ID, Davidson I, Godehardt E, Gillespie LD, Grodzicki T, Hartikainen S, Harwood RH, Iwarsson S, Kivelä SL, Lamb SE, Lukasik MF, Mulder S, Ocetkiewicz T, Pfeiffer K, Potter R, Reinke T, Richardson S, Robertson MC, Rojano X, Rubenstein LZ, Salonoja M, Salva A, Sekman E, Skalska A, Skeleton D, Stahl A, Strach M, Todd CJ.

\section{Author details}

${ }^{1}$ Warwick Clinical Trials Unit, University of Warwick, Gibbet Hill Campus, Coventry, UK. ${ }^{2}$ Kadoorie Critical Care Research Centre, John Radcliffe Hospital, University of Oxford, Headley Way, Oxford, UK. ${ }^{3}$ Robert-BoschHospital, Geriatric Rehabilitation Clinic, Auerbachstrasse 110, 70376 Stuttgart, Germany. ${ }^{4}$ Department of Medicine, Dunedin School of Medicine, University of Otago, PO Box 913, Dunedin 9054, New Zealand.

\section{Authors' contributions}

$S L$ and $C B$ had the concept for the original study, study design and analysis. $S L$ wrote the first draft of the paper and is the guarantor. LG contributed search strategies and to the study design, analysis and write up. JS and SF were independent reviewers in final testing process and performed the statistical analysis. KP developed and edited the different versions of the taxonomy and manual, and contributed to the drafting of the manuscript. RP participated in developing the taxonomy. All authors read and approved the final version of the manuscript.

\section{Competing interests}

The authors declare that they have no competing interests.

Received: 6 December 2010 Accepted: 17 May 2011 Published: 17 May 2011

\section{References}

1. Campbell AJ, Borrie MJ, Spears GF: Risk factors for falls in a communitybased prospective study of people 70 years and older. J Gerontol 1989, 44:M112-M117.

2. Craig P, Dieppe P, Macintyre S, Michie S, Nazareth I, Petticrew M, Medical Research Council Guidance: Developing and evaluating complex interventions: the new Medical Research Council guidance. BMJ 2008, 337:a1655.

3. Lamb SE, Fisher JD, Gates S, Potter R, Cooke MW, Carter YH: A national survey of services for the prevention and management of falls in the UK. BMC Health Serv Res 2008, 8:233.

4. Perera R, Heneghan C, Yudkin P: Graphical method for depicting randomised trials of complex interventions. BMJ 2000, 334:127-129.

5. Boutron I, Moher D, Altman DG, Schulz KF, Ravaud P, CONSORT Group: Extending the CONSORT statement to randomized trials of nonpharmacologic treatment: explanation and elaboration. Ann Intern Med 2008, 148:295-309.

6. The Prevention of Falls Network Europe. [http://www.profane.eu.org/].

7. Sartorius N: Methodologic problems of common terminology, measurement, and classification. 11. Modifications and new approaches to taxonomy in long-term care: advantages and limitations of the ICD. Med Care 1976, 14(Suppl 5):109-115.

8. Black N, Murphy M, Lamping D, McKee M, Sanderson C, Askham J, Marteau T: Consensus development methods. A review of best practice in creating clinical guidelines. J Health Serv Res Policy 1999, 4:236-248.

9. Gillespie LD, Robertson MC, Gillespie WJ, Lamb SE, Gates S, Cumming RG Rowe $\mathrm{BH}$ : Interventions for preventing falls in elderly people. Cochrane Database Syst Rev 2003, 4:CD007146.

10. Becker C, Kron M, Lindemann U, Sturm E, Eichner B, Walter-Jung B, Nikolaus T: Effectiveness of a multifaceted intervention on falls in nursing home residents. J Am Geriatr Soc 2003, 51:306-313.

11. Bischoff HA, Stähelin HB, Dick W, Akos R, Knecht M, Salis C, Nebiker M, Theiler R, Pfeifer M, Begerow B, Lew RA, Conzelmann M: Effects of vitamin
D and calcium supplementation on falls: a randomized controlled trial. J Bone Miner Res 2003, 18:343-351.

12. Carpenter GI, Demopoulos GR: Screening the elderly in the community: controlled trial of dependency surveillance using a questionnaire administered by volunteers. BMJ 1990, 300:1253-1256.

13. Carter ND, Khan KM, McKay HA, Petit MA, Waterman C, Heinonen A, Janssen PA, Donaldson MG, Mallinson A, Riddell L, Kruse K, Prior JC, Flicker $L:$ Community-based exercise program reduces risk factors for falls in 65-75 year old women with osteoporosis; Randomized controlled trial. CMAJ 2002, 167:997-1004.

14. Close J, Ellis M, Hooper R, Glucksman E, Jackson S, Swift C: Prevention of falls in the elderly trial (PROFET): a randomised controlled trial. Lancet 1999, 353:93-97.

15. Dawson-Hughes B, Harris SS, Krall EA, Dallal GE: Effect of calcium and vitamin $D$ supplementation on bone density in men and women 65 years of age or older. N Engl J Med 1997, 337:670-676.

16. Day L, Fildes B, Gordon I, Fitzharris M, Flamer H, Lord S: Randomised factorial trial of falls prevention among older people living in their own homes. BMJ 2002, 325:128.

17. Ebrahim S, Thompson PW, Baskaran V, Evans K: Randomized placebocontrolled trial of brisk walking in the prevention of postmenopausa osteoporosis. Age Ageing 1997, 26:253-260.

18. Fabacher D, Josephson K, Pietruszka F, Linderborn K, Morley JE, Rubenstien $L Z$ : An in-home preventive assessment program for independent older adults: a randomized controlled trial. J Am Geriatr Soc 1994, 42:630-638.

19. Gallagher EM, Brunt $\mathrm{H}$ : Head over heels: impact of a health promotion program to reduce falls in the elderly. Can J Aging 1996, 15:84-96.

20. Hornbrook MC, Stevens VJ, Wingfield DJ, Hollis JF, Greenlick MR, Ory MG: Preventing falls among community-dwelling older persons: results from a randomized trial. Gerontologist 1994, 34:16-23.

21. Jitapunkul S: A randomised controlled trial of regular surveillance in Thai elderly using a simple questionnaire administered by non-professional personnel. J Med Assoc Thai 1998, 81:352-356.

22. Latham NK, Anderson CS, Lee A, Bennett DA, Moseley A, Cameron ID, Fitness Collaborative Group: A Randomized, Controlled Trial of Quadriceps Resistance Exercise and Vitamin D in Frail Older People: The Frailty Interventions Trial in Elderly Subjects (FITNESS). J Am Geriatr Soc 2003, 51:291-299.

23. Lord SR, Ward JA, Williams P, Strudwick M: The effect of a 12-month exercise trial on balance, strength, and falls in older women: a randomized controlled trial. J Am Geriatr Soc 1995, 43:1198-1206.

24. Mayo NE, Gloutney L, Levy AR: A randomized trial of identification bracelets to prevent falls among patients in a rehabilitation hospital. Arch Phys Med Rehabil 1994, 75:1302-1308

25. McMurdo ME, Millar AM, Daly F: A randomized controlled trial of fall prevention strategies in old peoples' homes. Gerontology 2000, 46:83-87.

26. Nikolaus T, Bach M: Preventing falls in community-dwelling frail older people using a home intervention team (HIT): results from the Randomized Falls-HIT Trial. J Am Geriatr Soc 2003, 51:300-305.

27. Nowalk MP, Prendergast JM, Bayles CM, D'Amico FJ, Colvin GC: A randomized trial of exercise programs among older individuals living in two long-term care facilities: the FallsFREE program. J Am Geriatr SoC 2001, 49:859-865.

28. Pardessus V, Puisieux F, Di Pompeo C, Gaudefroy C, Thevenon A, Dewailly P: Benefits of home visits for falls and autonomy in the elderly. A randomized trial study. Am J Phys Med Rehabil 2002, 81:247-252.

29. Reinsch S, MacRae P, Lachenbruch PA, Tobis JS: Attempts to prevent falls and injury: a prospective community study. Gerontologist 1992, 32:450-456.

30. Robertson MC, Devlin N, Gardner MM, Campbell AJ: Effectiveness and economic evaluation of a nurse delivered home exercise programme to prevent falls. 1: Randomised controlled trial. BMJ 2001, 322:697-701.

31. Rubenstein LZ, Josephson KR, Trueblood PR, Loy S, Harker JO, Pietruszka FM, Robbins AS: Effects of a group exercise program on strength, mobility, and falls among fall-prone elderly men. J Gerontol A Biol Sci Med Sci 2000, 55:M317-M321.

32. Sato $Y$, Manabe $S$, Kuno $H$, Oizumi $K$ : Amelioration of osteopenia and hypovitaminosis $D$ by 1 alpha-hydroxyvitamin D3 in elderly patients with Parkinson's disease. J Neurol Neurosurg Psychiatry 1999, 66:64-68.

33. Tideiksaar R, Feiner CF, Maby J: Falls prevention: the efficacy of a bed alarm system in an acute-care setting. Mt Sinai J Med 1993, 60:522-527. 
34. Tinetti ME, Baker DI, McAvay G, Claus EB, Garrett P, Gottschalk M, Koch ML, Trainor K, Horwitz Rl: A multifactorial intervention to reduce the risk of falling among elderly people living in the community. New Eng J Med 1994, 331:821-827.

35. van Haastregt JC, Diedericks JP, van Rossum E, de Witte LP, Voorhoeve PM, Crebolder HF: Effects of a programme of multifactorial home visits on falls and mobility impairments in elderly people at risk: randomised controlled trial. BMJ 2000, 321:994-998.

36. van Rossum E, Frederiks CM, Philipsen H, Portengen K, Wiskerke J, Knipschild P: Effects of preventive home visits to elderly people. BMJ 1993, 307:27-32.

37. Wolf SL, Barnhart HX, Kutner NG, McNeely E, Coogler C, Xu T: Reducing frailty and falls in older persons: an investigation of Tai Chi and computerized balance training. Atlanta FICSIT Group. Frailty and Injuries: Cooperative Studies of Intervention Techniques. J Am Geriatr Soc 1996, 44:489-497.

38. Lamb S, Gates S, Fisher J, Cooke M, Carter YH, McCabe C: Scoping Exercise on Fallers' Clinics. Report to the National Co-ordinating Centre for NHS Service Delivery and Organisation R \& D (NCCSDO). 2007 [http://www. sdo.nihr.ac.uk/files/project/139-final-report.pdf].

39. International Organization for Standardization: Technical Aids for Persons with Disabilities - Classification and Terminology (ISO9999). 3 edition. Geneva; 2002.

40. International Labour Office (ILO): International Standard Classification of Occupations: ISCO-88 Geneva; 1988.

41. Organisation for Economic Co-operation and Development (OECD): Classification of Providers of Health Care (ICHA-HP). International Classification for Health Accounts 1.0 Paris; 2000.

42. ATC/DDD Index. [http://www.whocc.no/atcddd/].

43. ICF - International Classification of Functioning, Disabilty and Health. [http://www.who.int/classification/icf/en].

44. Armstrong AL, Oborne J, Coupland CA, Macpherson MB, Bassey EJ, Wallace WA: Effects of hormone replacement therapy on muscle performance and balance in post-menopausal women. Cli Sci (Lond) 1996, 91:685-690.

45. Buchner DM, Cress ME, de Lateur BJ, Esselman PC, Margherita AJ, Price R, Wagner $\mathrm{EH}$ : The effect on strength and endurance training on gait, balance, fall risk, and health services use in community-living older adults. J Gerontol A Biol Sci Med Sci 1997, 52:M218-M224.

46. Campbell AJ, Robertson MC, Gardner MM, Norton RN, Tilyard MW Buchner DM: Randomised controlled trial of a general practice programme of home based exercise to prevent falls in elderly women. BMJ 1997, 315:1065-1069.

47. Campbell AJ, Robertson MC, Gardner MM, Norton RN, Buchner DM: Psychotropic medication withdrawal and a home-based exercise program to prevent falls: a randomized, controlled trial. J Am Geriatr Soc 1999, 47:850-853.

48. Coleman EA, Grothaus LC, Sandhu N, Wagner EH: Chronic care clinics: a randomized controlled trial of a new model of primary care for frail older adults. J Am Geriatr Soc 1999, 47:775-783.

49. Cumming RG, Thomas M, Szonyi G, Salkeld G, O'Neill E, Westbury C, Frampton G: Home visits by an occupational therapist for assessment and modification of environmental hazards: a randomized trial of falls prevention. J Am Geriatr Soc 1999, 47:1397-1402.

50. Donald IP, Pitt K, Armstrong E, Shuttleworth H: Preventing falls on an elderly care rehabilitation ward. Clin Rehabil 2000, 14:178-185.

51. Gray-Donald K, Payette H, Boutier V: Randomized clinical trial of nutritional supplementation shows little effect on functional status among free-living frail elderly. J Nutr 1995, 125:2965-2971.

52. Jensen J, Lundin-Olsson L, Nyberg L, Gustafson Y: Fall and injury prevention in older people living in residential care facilities. A cluster randomized trial. Ann Intern Med 2002, 136:733-741.

53. Kenny RA, Richardson DA, Steen N, Bexton RS, Shaw FE, Bond J: Carotid sinus syndrome: a modifiable risk factor for nonaccidental falls in older adults (SAFE PACE). J Am Coll Cardiol 2001, 38:1491-1496.

54. Kingston $\mathrm{P}$, Jones $\mathrm{M}$, Lally $\mathrm{F}$, Crome P: Older people and falls : A randomized controlled trial of a health visitor (HV) intervention. Rev Clin Gerontol 2001, 11:209-214.

55. Lightbody E, Watkins C, Leathley M, Sharma A, Lye M: Evaluation of a nurse-led falls prevention programme versus usual care: a randomized controlled trial. Age Ageing 2002, 31:203-210.
56. McMurdo ME, Mole PA, Paterson CR: Controlled trial of weight bearing exercise in older women in relation to bone density and falls. BMJ 1997, 314:569.

57. Means KM, Rodell DE, O'Sullivan PS, Cranford LA: Rehabilitation of elderly fallers: pilot study of a low to moderate intensity exercise program. Arch Phys Med Rehabil 1996, 77:1030-1036.

58. Mulrow CD, Gerety MB, Kanten D, Cornell JE, DeNino LA, Chiodo L, Aguilar C, O'Neil MB, Rosenberg J, Solis RM: A randomized trial of physical rehabilitation for very frail nursing home residents. JAMA 1994, 271:519-524

59. Newbury JW, Marley JE, Beilby JJ: A randomised controlled trial of the outcome of health assessment of people aged 75 years and over. Med J Aust 2001, 175:104-107.

60. Pereira MA, Kriska AM, Day RD, Cauley JA, LaPorte RE, Kuller LH: A randomized walking trial in postmenopausal women: effects on physical activity and health 10 years later. Arch Intern Med 1998, 158:1695-1701.

61. Pfeifer M, Begerow B, Minne HW, Abrams C, Nachtigall D, Hansen C: Effects of a short-term vitamin $D$ and calcium supplementation on body sway and secondary hyperparathyroidism in elderly women. $J$ Bone Miner Res 2000, 15:1113-1118.

62. Ray WA, Taylor JA, Meador KG, Thapa PB, Brown AK, Kajihara HK, Davis C, Gideon P, Griffin MR: A Randomized Trial of a Consultation Service to Reduce Falls in Nursing Homes. JAMA 1997, 278:557-562.

63. Rubenstein LZ, Robbins AS, Josephson KR, Schulman BL, Osterweil D: The value of assessing falls in an elderly population. A randomized clinical trial. Ann Intern Med 1990, 113:308-316.

64. Ryan JW, Spellbring AM: Implementing strategies to decrease risk of falls in older women. J Gerontol Nurs 1996, 22:25-31.

65. Schnelle JF, Kapur K, Alessi C, Osterweil D, Beck JG, Al-Samarrai NR, Ouslander JG: Does an exercise and incontinence intervention save healthcare costs in a nursing home population? J Am Geriatr Soc 2003, 51:161-168.

66. Shaw FE, Bond J, Richardson DA, Dawson P, Steen IN, McKeith IG, Kenny RA: Multifactorial intervention after a fall in older people with cognitive impairment and dementia presenting to the accident and emergency department: randomised controlled trial. BMJ 2003, 326:73-75.

67. Steinberg M, Cartwright C, Peel N, Williams G: A sustainable programme to prevent falls and near falls in community dwelling older people: results of a randomised trial. J Epidemiol Community Health 2000, 54:227-232.

68. Stevens M, Holman CD, Bennett N, de Klerk N: Preventing falls in older people: outcome evaluation of a randomized controlled trial. J Am Geriatr Soc 2001, 49:1448-1455.

69. Vetter NJ, Lewis PA, Ford D: Can health visitors prevent fractures in elderly people? BMJ 1992, 304:888-890.

70. Wagner EH, La Croix AZ, Grothaus L, Leveille SG, Hecht JA, Artz K, Odle K, Buchner DM: Preventing disability and falls in older adults: a populationbased randomized trial. Am J Public Health 1994, 84:1800-1806.

71. Landis JR, Koch GG: The measurement of observer agreement for categorical data. Biometrics 1977, 33:159-174.

72. Gates S, Fisher JD, Cooke MW, Carter YH, Lamb SE: Multifactorial assessment and targeted intervention for preventing falls and injuries among older people in community and emergency care settings: systematic review and meta-analysis. BMJ 2008, 336:130-133.

73. Bischoff-Ferrari HA, Orav EJ, Dawson-Hughes B: Additive benefit of higher testosterone levels and vitamin D plus calcium supplementation in regard to fall risk reduction among older men and women. Osteoporos Int 2008, 19:1307-1314

74. Broe KE, Chen TC, Weinberg J, Bischoff-Ferrari HA, Holick MF, Kiel DP: A higher dose of vitamin $d$ reduces the risk of falls in nursing home residents: a randomized, multiple-dose study. J Am Geriatr Soc 2007 55:234-239.

75. Bunout D, Barrera G, Avendaño M, de la Maza P, Gattas V, Leiva L, Hirsch S: Results of a community-based weight-bearing resistance training programme for healthy Chilean elderly subjects. Age Ageing 2005 34:80-83.

76. Carter ND, Khan KM, McKay HA, Petit MA, Waterman C, Heinonen A, Janssen PA, Donaldson MG, Mallinson A, Riddell L, Kruse K, Prior JC, Flicker $L$ : Community-based exercise program reduces risk factors for falls in 65- to 75-year-old women with osteoporosis: randomized controlled trial. CMAJ 2000, 167:997-1004. 
77. Close J, Ellis M, Hooper R, Glucksman E, Jackson S, Swift C: Prevention of falls in the elderly trial (PROFET): a randomised controlled trial. Lancet 1999, 353:93-97.

78. Cumming RG, Ivers R, Clemson L, Cullen J, Hayes MF, Tanzer M, Mitchell P: Improving vision to prevent falls in frail older people: a randomized trial. J Am Geriatr Soc 2007, 55:175-181.

79. Harwood RH, Foss AJ, Osborn F, Gregson RM, Zaman A, Masud T: Falls and health status in elderly women following first eye cataract surgery: a randomised controlled trial. Br J Opthalmol 2005, 89:53-59.

80. Rubenstein LZ, Josephson KR, Trueblood PR, Loy S, Harker JO, Pietruszka FM, Robbins AS: Effects of a group exercise program on strength, mobility, and falls among fall-prone elderly men. J Gerontol A Biol Sci Med Sci 2000, 55:M317-M321.

81. Schoenfelder DP, Rubenstein $L M:$ An exercise program to improve fallrelated outcomes in elderly nursing home residents. App/ Nurs Res 2004 17:21-31.

82. Skelton D, Dinan S, Campbell M, Rutherford O: Tailored group exercise (Falls Management Exercise - FaME) reduces falls in communitydwelling older frequent fallers (an RCT). Age Ageing 2005, 34:636-639.

83. Altman DG: Practical Statistics for Medical Research. 1 edition. New York: Chapman and Hall; 1991, 404

84. Schulz R, Czaja SJ, McKay JR, Ory MG, Belle SH: Intervention taxonomy (ITAX): describing essential features of interventions. Am J Health Behav 2010, 34:811-821.

85. A Framework for development and evaluation of RCTs for Complex Interventions to Improve Health. [http://www.mrc.ac.uk/Utilities/ Documentrecord/index.htm?d=MRC003372].

86. Howe TE, Rochester L, Jackson A, Banks PM, Blair VA: Exercise for improving balance in older people. Cochrane Database Syst Rev 2007, 4: CD004963.

87. Cameron ID, Murray GR, Gillespie LD, Robertson MC, Hill KD, Cumming RG, Kerse N: Interventions for preventing falls in older people in nursing care facilities and hospitals. Cochrane Database Syst Rev 2010, 1:CD005465.

88. Gillespie LD, Robertson MC, Gillespie WJ, Lamb SE, Gates S, Cumming RG, Rowe $\mathrm{BH}$ : Interventions for preventing falls in elderly people. Cochrane Database Syst Rev 2009, 15:CD007146.

doi:10.1186/1745-6215-12-125

Cite this article as: Lamb et al: Reporting of complex interventions in clinical trials: development of a taxonomy to classify and describe fallprevention interventions. Trials 2011 12:125.

\section{Submit your next manuscript to BioMed Central and take full advantage of:}

- Convenient online submission

- Thorough peer review

- No space constraints or color figure charges

- Immediate publication on acceptance

- Inclusion in PubMed, CAS, Scopus and Google Scholar

- Research which is freely available for redistribution

Submit your manuscript at www.biomedcentral.com/submit 